\title{
Assessing ecosystem collapse risk in ecosystems dominated by foundation species: the case of fringe mangroves
}

Running title: Assessing risk of ecosystem collapse

Ashleigh Marshall1,2, Henrike Schulte to Bühne' ${ }^{2}$, Lucie Bland³, Nathalie Pettorelli

${ }^{1}$ Faculty of Life Sciences, University College London, Gower St, London WC1E 6BT, UK.

${ }^{2}$ Institute of Zoology, Zoological Society of London, Regent's Park, London NW1 4RY, UK.

${ }^{3}$ Centre for Integrative Ecology, School of Life and Environmental Sciences, Deakin University, Victoria 3121 Australia.

Corresponding author: Nathalie Pettorelli (Nathalie.Pettorelli@ioz.ac.uk)

Number of words (excluding the title, abstract, references, figure captions, and tables): 6301; 5 Tables, 3 Figures; Supplementary Materials: 3 Tables 


\section{ABSTRACT}

Ecosystem collapse, i.e. the endpoint of ecosystem decline, is a central concept of IUCN Red List of Ecosystems (RLE) assessments and the identification of ecosystems most vulnerable to global environmental change. Estimating collapse risk can be challenging for ecosystems reliant on a few dominant species to perform most of their functions because the range of suitable and feasible indicators is small. This study investigates the robustness and adequacy of the current RLE approach for risk assessments in such ecosystems, using a fringe mangrove ecosystem as a case study. Following the RLE protocol, we constructed a conceptual model of the key ecosystem processes for the Philippines' fringe mangrove forests. Satellite remote sensing data and existing maps of mangrove forests were then combined to assess the spatial distribution of the ecosystem considered (Criteria $A$ and $B$ ), while the Normalized Difference Vegetation Index was used to assess biotic degradation (Criterion D). Insufficient data were available to assess Criteria $C$ (environmental degradation) and $\mathrm{E}$ (quantitative analysis). Overall, the ecosystem was assessed as 'Least Concern' based on extensive geographic distribution and only weak support for declines in extent. Criterion D was classed as 'Data Deficient' since there was no clear relationship between the vegetation index and fringe mangrove degradation. Our results demonstrate how gaps in our appreciation and understanding of the structure and functioning of ecosystems are more likely to impede risk assessments of ecosystems characterised by a small number of foundation species, due to the low level of redundancy between candidate indicators available for their assessments. Satellite remote sensing combined with derivation of explicit conceptual ecosystem models provides a way to structure efforts to identify suitable indicators as well as opportunities to overcome many of these challenges, even for relatively data-poor ecosystems.

KEY WORDS: Ecosystem collapse, foundation species, fringe mangroves, IUCN Red List of Ecosystems 


\section{INTRODUCTION}

Ecosystems have immense intrinsic value whilst also providing vital ecosystem services on which human life depends (Millennium Ecosystem Assessment, 2005). Human activities have however led to degradation of many ecosystems globally (Hansen et al., 2013; Davidson, 2014; Haddad et al., 2015), reducing their capacity to support life. Degradation can eventually lead to ecosystem collapse, a state in which ecosystems lose their defining abiotic and biotic features to the extent that their identity has been irremediably changed. Ecosystem collapse amounts to a transition into a novel ecosystem, characterised by different biota and mechanisms of organisation and/or altered abundance, interactions, and ecological functions of the remaining original biota (Jackson et al., 2001; Folke et al., 2004; Bland, Keith, Miller, Murray \& Rodríguez, 2016). Ecosystem collapse can have severe consequences for biodiversity, ecosystem services and subsequently human welfare (Dobson et al., 2006; but see Raudsepp-Hearne et al., 2010), meaning that there is currently increasing interest in being able to avoid them whenever possible.

Predicting where and when transitions into novel ecosystems may occur is however often difficult (Keith, 2015) since the number of species and processes that can change before an ecosystem loses its original identity has rarely been quantified (Boitani, Mace \& Rondini, 2015). Three years ago, the International Union for the Conservation of Nature (IUCN) adopted the Red List of Ecosystems (RLE) Categories and Criteria as a robust and consistent tool for monitoring the risk status of ecosystems in order to plan appropriate conservation actions (Keith et al., 2013; Bland et al., 2016). Key to the RLE assessments is the concept of ecosystem collapse, defined there as the endpoint to ecosystem decline, "when it is virtually certain that its defining biotic or abiotic features are lost from all occurrences, and the characteristic native biota are no longer sustained" (Bland et al. 2016). Two of the risk assessment criteria assess spatial symptoms of ecosystem collapse through declines in distribution (Criterion A) and restricted distribution (Criterion B); two criteria assess functional symptoms of ecosystem collapse through environmental degradation (Criterion $\mathrm{C}$ ) and biotic disruption (Criterion $\mathrm{D}$ ); the final criterion (Criterion E) evaluates quantitative estimates of the risk of collapse through the integration of multiple threats and symptoms into models of ecosystem dynamics 
(Bland et al. 2016). The RLE assessment is based on a conceptual model which summarises the most important biotic and abiotic components of a given system, as well as significant ecosystem functions and processes. This model facilitates characterising all relevant pathways to collapse, as well as choosing appropriate variables to monitor ecosystem degradation.

But is this general approach robust enough to help detect ecosystem collapse risk for ecosystems dependent on a few dominant, so-called "foundation species", to perform most of their functions? Relatively minor reductions in the abundance of a foundation species could indeed have critical consequences for the functioning of these ecosystems, with significant impacts on associated biota, even before the characteristic native biota is entirely lost (Dayton, 1972; Ellison et al., 2005). In this situation, monitoring the foundation species provides a robust estimate of collapse risk only if changes that affect ecosystem functioning are captured. For instance, merely monitoring tree cover to assess the condition of a forest will not be enough to robustly assess collapse risk if the functions supported by trees (e.g. as habitat for other biota) vary with stand or age structure (Burns et al., 2015). Non-foundation species or the abiotic environment may moreover change in a way that fundamentally alters ecosystem functioning, but unless the foundation species are significantly affected, the ecosystem may not appear to have changed. For instance, defaunation of structurally intact forests alters processes such as seed dispersal and tree seedling recruitment (Stoner, Vulinec, Wright \& Peres, 2007; Terborgh et al., 2008), resulting in changes in the relative abundance of tree species at the seedling stage (Terborgh et al., 2008; Effiom, Nuñez-Iturri, Smith, Ottosson \& Olsson, 2013). Due to the long generation time of trees, recently defaunated forests are difficult to distinguish from forests with a full set of large vertebrates, in terms of tree distribution and composition (Harrison et al., 2013).

To investigate the robustness of the current RLE approach for collapse risk assessments in ecosystems dependent on a few foundation species to perform most of their functions, we here apply the RLE protocol to fringe mangrove forests in the Philippines. Fringe mangrove forests are tide-dominated mangrove forests (i.e. they have the highest tidal inundation frequency), as opposed to river-dominated or inland (basin) mangrove forests (Ewel, Twilley \& Ong's (1998). Fringe mangrove forests 
have distinct abiotic settings, as well as distinct ecosystem composition and functioning compared to riverine and basin mangroves; distinctive features include consistently high salinity, relatively higher abundance of migratory birds, and the highest carbon export values among all mangrove forest types (Ewel, Twilley \& Ong, 1998). Taken together, this suggests they are best conceptualised as a separate ecosystem. In the Philippines, fringe mangrove forests are dominated by only two true mangrove species (Avicennia marina and Sonneratia alba; Ricklefs \& Latham, 1993; FAO, 2007; Sinfuego \& Buot, 2008, 2014), making them an ideal case study of ecosystems dominated by few foundation species. Over $50 \%$ of the total mangrove area in the Philippines has reportedly been lost in the last century, and mangrove forests in general are continuing to disappear from South East Asia at an estimated rate of 3.6-8.1\% per year (Polidoro et al. 2010; Long, Napton, Giri \& Graesser, 2014; Hamilton \& Casey, 2016); this suggests that fringe mangroves, like other types of mangroves, could be at an increased risk of collapse. As they provide vital ecosystem services including coastal protection, provision of raw materials, and carbon sequestration, this would not only result in loss of biodiversity, but would likely have devastating consequences for humans, both locally and worldwide (Garcia, Malabrigo \& Gevaña, 2014).

\section{METHODS}

A detailed description of the RLE assessment process is provided by Bland et al. (2016) and Murray et al. (2016). In short, this entails describing the fringe mangrove ecosystem, identifying suitable variables to assess ecosystem degradation, and defining ecosystem collapse as bounded thresholds in these variables. These are used to assign one of eight risk categories to each criterion: Collapsed (CO), Critically Endangered (CR), Endangered (EN), Vulnerable (VU), Near Threatened (NT), Least Concern (LC), Data Deficient (DD), or Not Evaluated (NE). The overall risk category for the ecosystem is the highest overall risk category assigned in any criterion. 


\subsection{Ecosystem Description}

Information from published literature was compiled to describe the functioning of fringe mangroves in the Philippines. From this, the key ecosystem dynamics and threatening processes were identified to construct a conceptual model (Figure 1) to support the identification of suitable variables for assessing ecosystem decline. Following Bland and colleagues' protocol (2016), we identified key abiotic and biotic ecosystem components, processes and threats that influence the integrity of fringe mangrove forests, building on from previous models by Lugo \& Snedaker (1974) and Twilley et al. (1996). An abbreviated ecosystem description is provided in the Supplementary Material (Table S1.1 in Supplementary Materials). Fringe mangroves in the Philippines are dominated by salt-tolerant true mangroves of the genera Avicennia, Sonneratia, Aegiceras, and Rhizophora, in particular Avicennia marina and Sonneratia alba (Ricklefs \& Latham, 1993; FAO, 2007; Sinfuego \& Buot, 2008, 2014). These species drive most ecosystem processes and functions in fringe mangrove forests: they provide nursery habitat for fish and shrimp species (Farley, Batker, de la Torre \& Hudspeth, 2010; Brander et al., 2012; Buelow \& Sheaves, 2015); their roots play a significant role in sedimentation control (Alongi, 2008); they also generate large amounts of organic matter, contributing to local and global nutrient and carbon cycles (Ewel et al., 1998; Kathiresan \& Bingham, 2001; Barbier et al., 2011). Counterintuitively, mangrove litter has been shown to have little importance for local secondary productivity (Heithaus, Heithaus, Heithaus, Burkholder \& Layman, 2011). Few animal species are exclusive to fringe mangroves, with many only present during parts of their life cycle, particularly migratory birds (Table S1.2 in Supplementary Materials; Ewel et al., 1998), and thus have a limited functional importance. Crucially, whilst fiddler and sesarmid crabs have been described as keystone species for fringe mangrove ecosystems, these ecosystems have been shown to be stable even at low density of these crabs (Lee, 1998). Crab species richness and community composition have been found to be poor predictors of mangrove tree species richness, forest structure and anthropogenic pressure; this suggests that crab density is not a useful bioindicator for the stability of fringe mangroves (Geist, Nordhaus \& Hinrichs, 2012). 


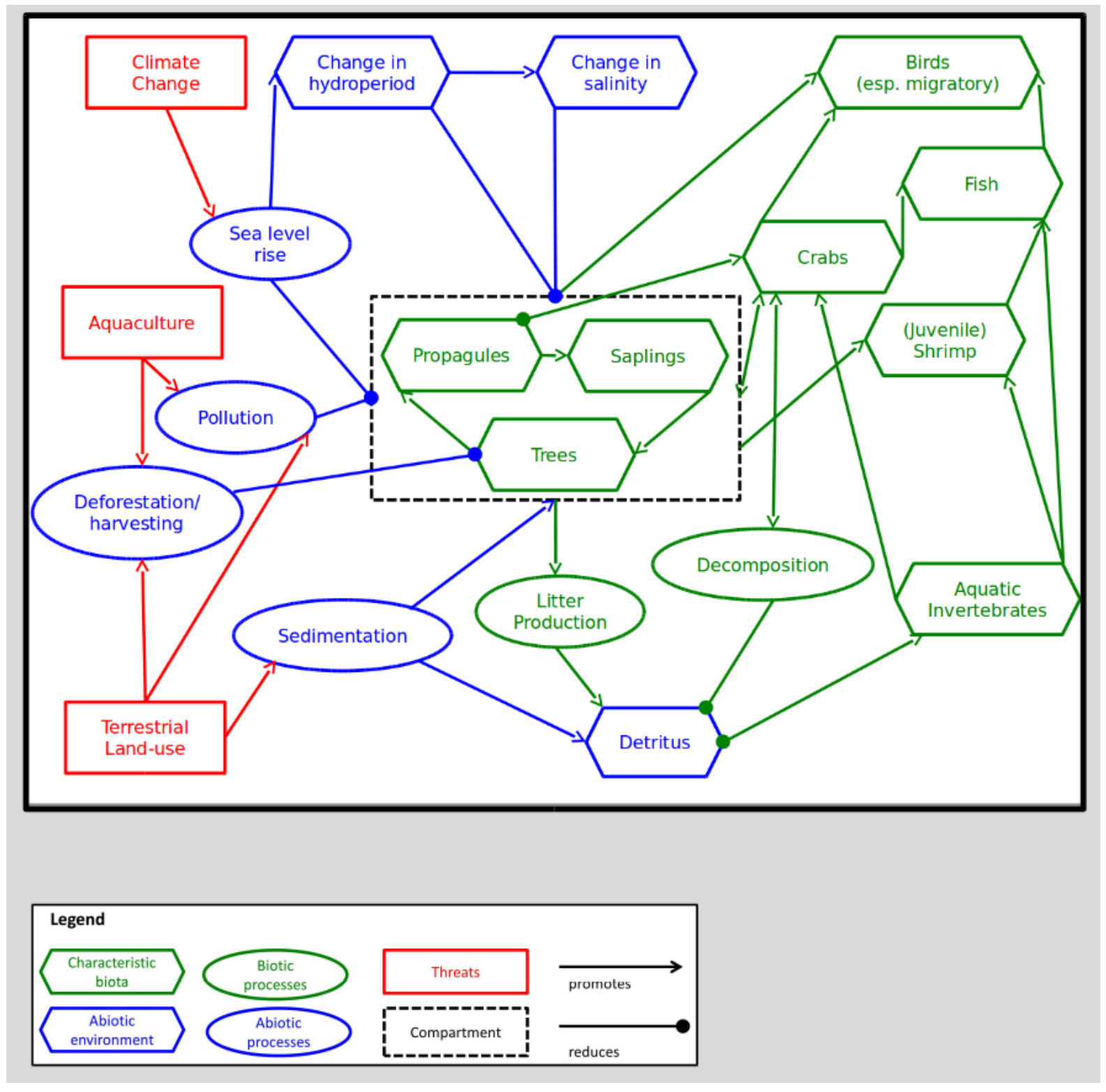

Figure 1. A simplified cause-and-effect conceptual model of the ecological processes most relevant to the Philippines' fringe mangrove ecosystem risk assessment. The black box indicates different life stages of the mangrove trees. Red boxes indicate threats, green and blue hexagons represent the characteristic biota and the abiotic environment respectively, and green and blue ovals represent the biotic and abiotic processes respectively. Arrows indicate positive relationships while dots indicate negative relationships. 


\subsection{Ecosystem Collapse indicators}

Fringe mangrove forests have clear bottom-up trophic regulation, with non-dominant species (fish, crabs, shrimps) playing a relatively small ecological role. As a result, assessing spatial and functional symptoms of collapse is here solely based on monitoring mangrove species (Table 1), with mangrove loss or degradation seen as the dominant pathway to collapse (Figure 1; Lee, 1998; Geist, Nordhaus \& Hinrichs, 2012). Specifically, it is assumed that the absence of true mangroves signifies the transition of the fringe mangrove forest into a collapsed or novel ecosystem, with the leading threat causing collapse dictating the post-transition ecosystem, e.g. persistent sea level rise potentially resulting in a transition to peat swamp forest (IUCN, 2012) or deforestation for aquaculture resulting in a transition to brackish water ponds (Primavera \& Esteban, 2008). 
Table 1. Overview over collapse thresholds, variables and underlying data used to assess Philippines' fringe mangrove forests according to the IUCN Red List of Ecosystems assessment. The description of the criteria was adapted from Bland and colleagues (2016).

\begin{tabular}{|c|c|c|c|c|}
\hline Criterion & Purpose & Variable & $\begin{array}{l}\text { Collapse } \\
\text { threshold }\end{array}$ & $\begin{array}{l}\text { Underlying } \\
\text { data }\end{array}$ \\
\hline $\begin{array}{l}\text { A (Reduction in } \\
\text { geographic } \\
\text { distribution) }\end{array}$ & $\begin{array}{l}\text { Identifies ecosystems } \\
\text { that are undergoing } \\
\text { declines in area, most } \\
\text { commonly due to } \\
\text { threats resulting in } \\
\text { ecosystem loss and } \\
\text { fragmentation. }\end{array}$ & $\begin{array}{l}\text { Change in the } \\
\text { distribution of } A \text {. } \\
\text { marina and S. alba }\end{array}$ & $100 \%$ loss & $\begin{array}{l}\text { Maps of } \\
\text { mangrove } \\
\text { forests from } \\
2000,2010 \text { and } \\
2016\end{array}$ \\
\hline $\begin{array}{l}\text { B (Restricted } \\
\text { geographic } \\
\text { distribution) }\end{array}$ & $\begin{array}{l}\text { Identifies ecosystems } \\
\text { with small distributions } \\
\text { that are susceptible to } \\
\text { spatially explicit threats } \\
\text { and catastrophes. }\end{array}$ & $\begin{array}{ll}\text { Current } & \text { fringe } \\
\text { mangrove } & \\
\text { distribution } & \end{array}$ & $\begin{array}{l}\text { Extent and } \\
\text { area of } \\
\text { occurrence } \\
\text { are 0 }\end{array}$ & $\begin{array}{l}\text { Maps of } \\
\text { mangrove } \\
\text { forests from } \\
2016\end{array}$ \\
\hline \multirow[t]{2}{*}{$\begin{array}{l}\text { C (Environmental } \\
\text { Degradation) }\end{array}$} & \multirow{2}{*}{$\begin{array}{l}\text { Identifies ecosystems } \\
\text { that are undergoing } \\
\text { environmental } \\
\text { degradation. }\end{array}$} & $\begin{array}{l}\text { Change } \\
\text { hydroperiod }\end{array}$ & NA & NA \\
\hline & & Change in sealevel & NA & NA \\
\hline \multirow[t]{2}{*}{$\begin{array}{l}\text { D (Disruption of } \\
\text { biotic processes } \\
\text { and interactions) }\end{array}$} & \multirow[t]{2}{*}{$\begin{array}{l}\text { Identifies ecosystems } \\
\text { that are undergoing } \\
\text { loss or disruption of } \\
\text { key biotic processes or } \\
\text { interactions. }\end{array}$} & $\begin{array}{l}\text { Primary productivity } \\
\text { of } A \text {. marina and } S \text {. } \\
\text { alba }\end{array}$ & $50-100 \%$ loss & $\begin{array}{l}\text { NDVI } \\
\text { series }\end{array}$ \\
\hline & & $\begin{array}{l}\text { Seedling } \\
\text { recruitment of } A \text {. } \\
\text { marina and S. alba }\end{array}$ & NA & NA \\
\hline $\begin{array}{l}\text { E (Quantitative } \\
\text { risk analysis) }\end{array}$ & $\begin{array}{l}\text { Allows for an integrated } \\
\text { evaluation of multiple } \\
\text { threats, symptoms, and } \\
\text { their interactions. }\end{array}$ & $\begin{array}{l}\text { Quantitative risk } \\
\text { model }\end{array}$ & NA & NA \\
\hline
\end{tabular}


When it comes to assessing spatially explicit RLE criteria (namely criterion A, which assesses changes in spatial distribution over a given timeframe, and criterion B, which assesses the size of the current ecosystem distribution; Bland et al., 2016), fringe mangroves were considered collapsed when their mapped distribution declines to zero (100\% loss). Specifically, the collapse of the fringe mangrove ecosystem is defined as the loss of the characteristic native biota, Avicennia marina and Sonneratia alba, since it entails loss of key ecological and ecosystem processes, such as decomposition and sediment-trapping, and the ecosystem can no longer sustain other characteristic biota such as fish, crabs, and migratory birds.

Assessing functional criteria was more challenging. A possible indicator of environmental degradation (Criterion $\mathrm{C}$ ) highlighted by the conceptual model (Figure 1 ) is a change in hydroperiod. However, there is a lack of both baseline information and understanding of the direct influences of hydroperiod on fringe mangrove forests, hence thresholds for collapse cannot be established. Alternatively, relative sea-level rise has been suggested to be the greatest threat to mangroves (Gilman, Ellison, Duke \& Field, 2008; Giri et al., 2011). Variables such as shoreline geomorphology, sedimentation rates and biotic processes play a large role in how mangrove forests respond to rising sea levels (Krauss et al., 2008; Soares, 2009; Lee et al., 2014). There are gaps in our understanding of how biological and physical processes interact to accommodate sea-level rise (Alongi et al, 2008; Gilman et al., 2008; Krauss et al., 2008), making it difficult to quantify how Philippines' fringe mangrove forests will be affected by sea-level rise. Ultimately, we therefore could not set thresholds for collapse for any of the possible indicators we identified for Criterion C.

Net primary productivity (NPP) was identified as a suitable indicator for assessing ecosystem degradation due to disruption of biotic processes and interactions (Criterion D). Fringe mangrove forests are indeed highly productive ecosystems (Kristensen, Bouillon, Dittmar \& Marchand, 2008), and productivity has been suggested to increase with stand age and when mangroves are more abundant, showing a strong link between the condition of these characteristic native biota and the productivity of the ecosystem (Kristensen et al., 2008; Brander et al., 2012; Alongi, 2014). We consider the Philippines' fringe mangrove ecosystem to be 
collapsed when its NPP declines by $50-100 \%$. Such a bounded estimate represents a range of plausible alternative values for the measure in order to characterise the uncertainty involved in setting thresholds to describe collapsed states (Bland et al., 2016). In this case, the large bounds are required in order to account for the relatively low sensitivity of the measure. At the most extreme end, the upper bound $(100 \%)$ represents the complete loss of net primary productivity (e.g. if mangroves are replaced by built-up area or bare ground). The lower bound is necessary to account for the collapse of the ecosystem via replacement by a novel ecosystem that has a lower NPP; in this case, fringe mangroves are usually replaced by aqua- or agricultural and urban production systems (Primavera, 2000, Lee et al., 2014, Garcia et al., 2014), which have much lower NDVI. This bound also acknowledges that there are natural fluctuations in mangrove productivity over time (both intra- and interannual, Day et al., 1996), which are unrelated to ecosystem collapse. We here use the Normalized Difference Vegetation Index (NDVI) as a proxy for net primary productivity (Pettorelli, 2013), as this was the only available information for the time period and spatial extent considered. An alternative indicator for biotic disruption is mangrove seedling dispersal, along with their establishment and recruitment to the sapling stage, which are critical stages in the mangrove life cycle (Padilla, Fortes, Duarte, Terrados \& Kamp-Nielsen, 2004). A Philippine fringe mangrove ecosystem can be considered collapsed when the rate of seedling recruitment falls to 0 . However, there are no data available to assess recruitment rates across the Philippines, precluding the use of this indicator in the present assessment. Lastly, although fringe mangrove ecosystems support dense assemblages of birds, crabs, insects, fish, and prawns (Ewel et al., 1998; Ellison, 2005; Nagelkerken et al, 2008), none of these species are reliably linked to roles supporting the sustainability of the ecosystem (Duke, Ball \& Ellison, 1998; Lee, 1998; Heithaus et al., 2011; Geist, Nordhaus \& Hinrichs, 2012), hence changes in their respective abundances and overall species richness would only serve as additional measures of ecosystem productivity and not reliable indicators of risk of collapse.

There is currently no existing quantitative risk model of the Philippines' fringe mangrove forests (Criterion E), primarily due to the lack of relevant local information for this particular ecosystem and location. 


\subsection{Data}

Criteria A/B: Landsat imagery was used to map the spatial distribution and assess the areal extent of the Philippines' fringe mangrove forests in 2016 via supervised land cover classification, and was compared to distribution and extent of fringe mangroves in 2000 and 2010, produced by Long \& Giri (2011) and Long, Napton, Giri \& Graesser (2014) respectively. Image processing and analysis was conducted in R v. 3.2.5 or 3.3.3 (R Core Team, 2016) or QGIS v. 2.18.3 (QGIS Development Team, 2016) unless otherwise stated. Surface reflectance data from Landsat 8 was downloaded from the United States Geological Survey (USGS) (http://earthexplorer.usgs.gov/). These scenes have a spatial resolution of $30 \mathrm{~m}$ and are pre-processed to at-surface reflectance level using the Landsat Surface Reflectance Code (LaSRC) (Vermote, Justice, Claverie \& Franch, 2016). Scenes were restricted to November-May 2016 to exclude the rainy season and limit cloud cover; the majority of scenes used had $<10 \%$ cloud cover. Where persistent cloud rendered obtaining sufficiently clear scenes impossible, multiple images were mosaicked to obtain a single scene (Long \& Giri, 2011); it was intermittently necessary to use imagery from 2015 (Table S1.3 in Supplementary Materials).

Clouds and cloud shadows were masked from each scene using the fmask product provided with the Landsat 8 surface reflectance data (Connette, Oswald, Songer \& Leimgruber, 2016). Where necessary, images were reprojected to WGS 84/UTM zone 51 before mosaicking, using the gdalwarp utility in GDAL v. 1.11.4 (GDAL Development Team, 2016). To reduce data volume and improve overall classification accuracy, only areas where mangroves are most likely to occur were retained for subsequent analysis. Specifically, only areas falling within a 10,000 m buffer around the coastline (based on the Philippines' administrative boundaries from the Global Administrative Areas Database; Hijmans, Garcia \& Wieczorek, 2015) were retained. This buffer encompassed the previous 2000/2010 mangrove areas within a substantial margin, whilst excluding the large areas inland where fringe mangroves are unlikely occur.

Following Connette et al. (2016), high-resolution imagery from Google Earth ${ }^{\mathrm{TM}}$ was used to create training data for the supervised land cover classification representative of the land-cover types to be classified from across the Philippines. 
To be consistent with the time period of the assessment, training data was exclusively derived from high-resolution imagery from 2015-2016. Previous mangrove distributions were used to support identification of mangroves. The final training dataset contained 125-175 polygons from each target land-cover class ('Mangrove', 'Water', 'Barren', 'Non-mangrove'). The NDVI (Pettorelli, 2013) and Modified Normalised Difference Water Index (MNDWI; Xu, 2006) were calculated and used together with the original Landsat 8 bands 1-7 as predictors in the land cover classification process. A supervised classification was performed using a Random Forest algorithm implemented in the R package 'Rstoolbox' (Leutner \& Horning, 2010). 1500 samples per land cover class were randomly selected from the training data and split into 70\% independent training data and 30\% validation data (Wegmann, Leutner \& Dech, 2016).

To eliminate the majority of non-fringe mangrove forest from the mangrove map of 2016, pixels classified as mangroves outside a $2500 \mathrm{~m}$ buffer around the coastline were discarded. The size of this buffer was selected so that it included all mangrove forests (basin, riverine, fringe) mapped in 2000 (Long \& Giri, 2011) and 2010 (Long, Napton, Giri \& Graesser, 2014). A $200 \mathrm{~m}$ buffer of rivers created from a shapefile of the Philippines' waterways (www.mapcruzin.com) was used to exclude mangroves that were likely riverine. The buffer was not applied to areas less than $200 \mathrm{~m}$ from the coastline to avoid excluding coastal fringe mangrove forests that extended into riverine areas. Basin forests were excluded by manually removing sheltered areas (e.g. lagoons) and mangrove forests lacking coastline-adjacent boundaries. The procedure was used to extract fringe mangrove distributions from the 2000 and 2010 mangrove distributions.

Criterion D: NDVI MOD13A1 data from the Moderate-resolution Imaging Spectroradiometer (MODIS) covering the study area from March 2000 to December 2016 was downloaded from USGS via the R package 'MODIS' (Mattiuzzi \& Detsch, 2017). This data is provided every 16 days at $500 \mathrm{~m}$ spatial resolution. The NDVI and quality layer were extracted and the tiles mosaicked and masked to remove cloud pixels as indicated by the quality layer (Solano, Didan, Jacobson \& Huete, 2010 ), then cropped to areas where fringe mangroves occurred in 2000 , yielding a 
17-year time-series of NDVI values for areas classified as fringe mangrove areas in 2000.

\subsection{Analyses}

Criteria A/B: To inform Criterion A, the 2000, 2010 and 2016 fringe mangrove distributions were compared to quantify declines in spatial distribution. The distributions from 2000-2010 and 2000-2016 were used to assess the reduction in geographic distribution of the ecosystem as percentage area change. As the data does not fit the 50-year timeframe for an assessment, the proportional rate of decline (PRD) and absolute rate of decline (ARD) were calculated using equations (1) and (2) and used to estimate the area in 2050, 50 years since the first observed data point (Murray et al., 2016).

$$
\begin{aligned}
& P R D=100 \times\left(1-\left(\frac{\text { Area.t } 2}{\text { Area. } t 1}\right)^{\left(\frac{1}{\text { Year.t } 2-\text { Year. } 11}\right)}\right) \\
& A R D=\frac{-(\text { Area.t } 2 \text {-Area.t } 1)}{(\text { Year.t } 2 \text { Year.t } 1)}
\end{aligned}
$$

To inform subcriteria $B 1$ and $B 2$, the extent of occurrence (EOO) of fringe mangrove forests in 2016 was calculated as the area of a minimum convex polygon including all ecosystem occurrences, and the area of occupancy (AOO) was assessed by applying a grid of $10 \times 10-\mathrm{km}$ cells and selecting cells in which the ecosystem covered more than $1 \%\left(1 \mathrm{~km}^{2}\right)$ of the cell area (Bland et al., 2016). The $1 \%$ rule was used to prevent inflation of the $\mathrm{AOO}$ due to the large number of small, dispersed patches of fringe mangrove forest which may not substantially offset risks (Keith et al., 2013).

Criterion D: For each pixel, linear trends in mean NDVI between 2000 and 2016 were calculated using the Annual Aggregated Time Series method (Forkel et al., 2013) using the R package 'greenbrown' (Forkel \& Wutzler, 2015); the results were inspected visually in QGIS to investigate the spatial distribution of the trends and identify any relationship between trends and fringe mangrove forests degradation. Additionally, annual mean NDVI values in 2050 were estimated assuming either 
ARD or PRD (Murray et al., 2016). To assess the relative severity of the projected changes in NDVI, these were expressed as a percentage of the NDVI values indicating ecosystem collapse (both for the $50 \%$ and the $100 \%$ threshold).

\section{RESULTS}

Fringe mangroves were successfully identified by our land cover classification approach, with an overall classification accuracy of $88.1 \%$ (Kappa coefficient: 0.8414; Table 2). The extent of the Philippines' fringe mangrove forests in 2000 , 2010, and 2016 was estimated as $2038 \mathrm{~km}^{2}, 1924 \mathrm{~km}^{2}$, and $2538 \mathrm{~km}^{2}$ respectively. The resulting estimates of percentage area change range from a $28 \%$ loss to a $99 \%$ gain (Table 3). A $28 \%$ loss is within $10 \%$ of the threshold for the Vulnerable category, qualifying the ecosystem for Near Threatened status; however, the wide range makes Least Concern the most plausible category under subcriterion A2, especially since the estimates based on a longer time period predict an increase in area. Due to the absence of quantitative past data and historical data respectively, subcriteria A1 and A3 were assessed as Data Deficient (Table 4).

Table 2. Confusion matrix for the Random Forest Classification of the 2016 Landsat 8 imagery. 'Barren' training polygons contained representations of barren land in the form of empty fields or sandy areas; 'Mangrove' training polygons contained representations of mangrove forest; 'Non-mangrove' training polygons contained representations of terrestrial non-mangrove vegetation; 'Water' training polygons contained representations of water bodies and ocean areas. 


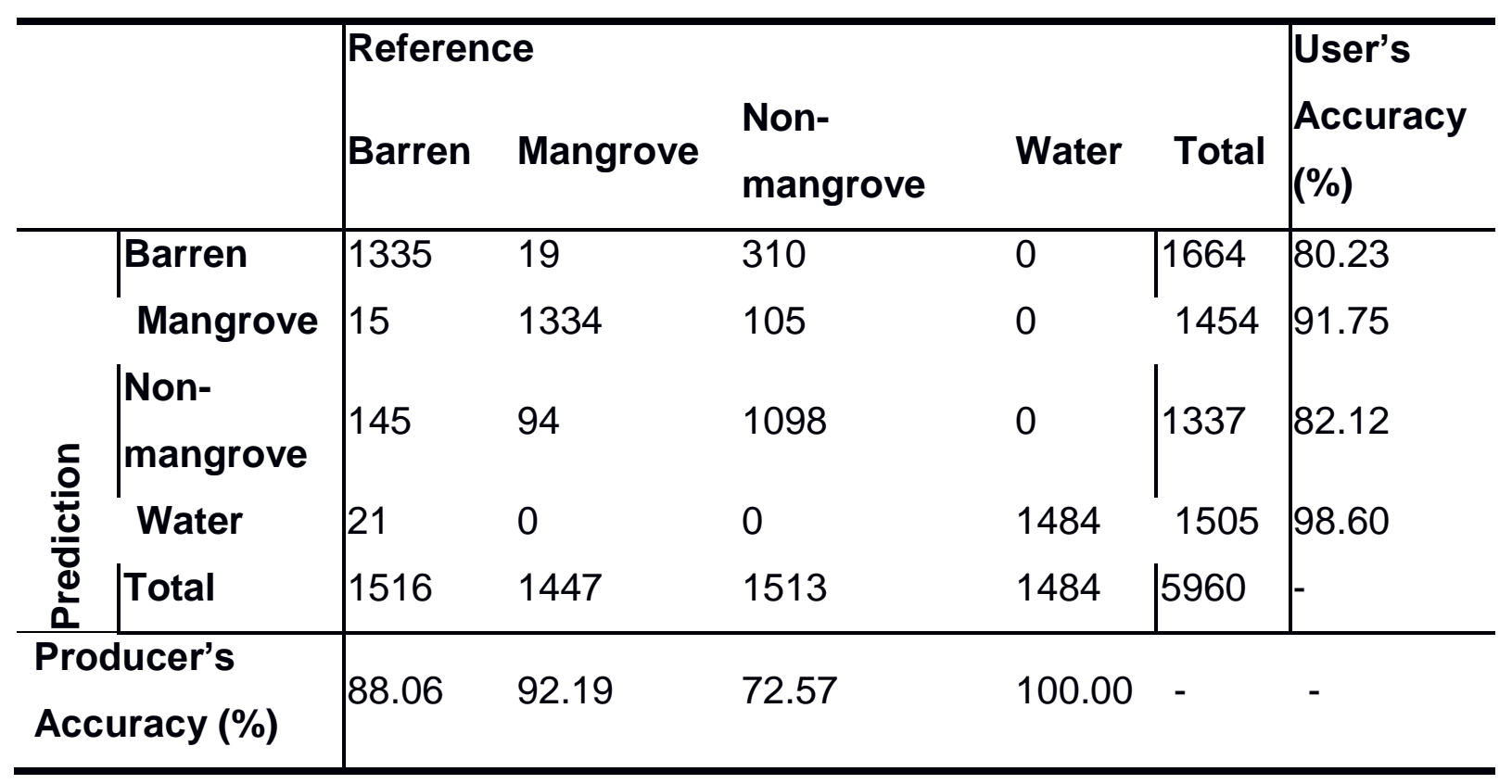

Table 3. Comparison of the Philippines' fringe mangrove forest distributions from 2000-2010 and 2000-2016 and resulting estimates of percentage area change over a 50 -year period from 2000 and 2050.

\begin{tabular}{|c|c|c|}
\hline & $2000-2010$ & $2000-2016$ \\
\hline Proportional Rate of Decline (PRD) & 0.57 & -11.38 \\
\hline Absolute Rate of Decline (ARD) & 11.34 & -31.25 \\
\hline$\%$ Area Change & $-5.56 \%$ & $+24.54 \%$ \\
\hline Area in 2050 (assuming PRD) & $1530.52 \mathrm{~km}^{2}$ & $4045.81 \mathrm{~km}^{2}$ \\
\hline Area in 2050 (assuming ARD) & $1470.83 \mathrm{~km}^{2}$ & $3600.58 \mathrm{~km}^{2}$ \\
\hline $\begin{array}{l}\% \text { Area Change 2000-2050 (assuming } \\
\text { PRD) }\end{array}$ & $-24.90 \%$ & $+98.53 \%$ \\
\hline $\begin{array}{l}\% \text { Area Change 2000-2050 (assuming } \\
\text { ARD) }\end{array}$ & $-27.82 \%$ & $+76.69 \%$ \\
\hline
\end{tabular}


Table 4. Overview over the IUCN Red List of ecosystem assessment results for fringe mangrove forests in the Philippines. $L C=$ Least Concern; DD = Data Deficient.

\begin{tabular}{lllllll}
\hline Criterion & A & B & C & D & E & Overall \\
\hline Sub-criterion 1 & A1: DD & B1: LC & C1: DD & D1: DD & E: DD & LC
\end{tabular}

$\begin{array}{lllll}\text { Sub-criterion } 2 & \text { A2: LC } & \text { B2: LC } & \text { C2: DD } & \text { D2: DD }\end{array}$

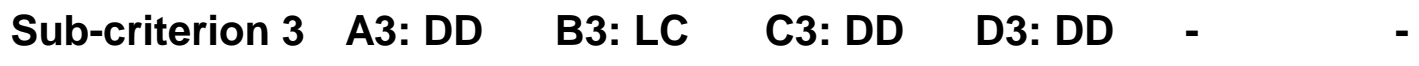


The EOO of the Philippines' fringe mangrove ecosystem was estimated to reach $1,131,150 \mathrm{~km}^{2}$, and the $\mathrm{AOO}$ of the ecosystem was $62110 \times 10-\mathrm{km}$ grid cells, resulting in an assessment of Least Concern under subcriteria B1 and B2 respectively (Figure 2). The significant threats likely to cause collapse of the ecosystem over the next two decades are likely to affect forests individually rather than impacting the entire extent of the Philippines in one event. The number of threat-defined locations ("a geographically or ecologically distinct area in which a single threatening event can rapidly affect all occurrences of an ecosystem type", Bland et al., 2016), was estimated to be larger than 5. This indicated that spatial autocorrelation of threats is likely to be low, and resulted in an assessment of Least Concern under subcriterion B3. 


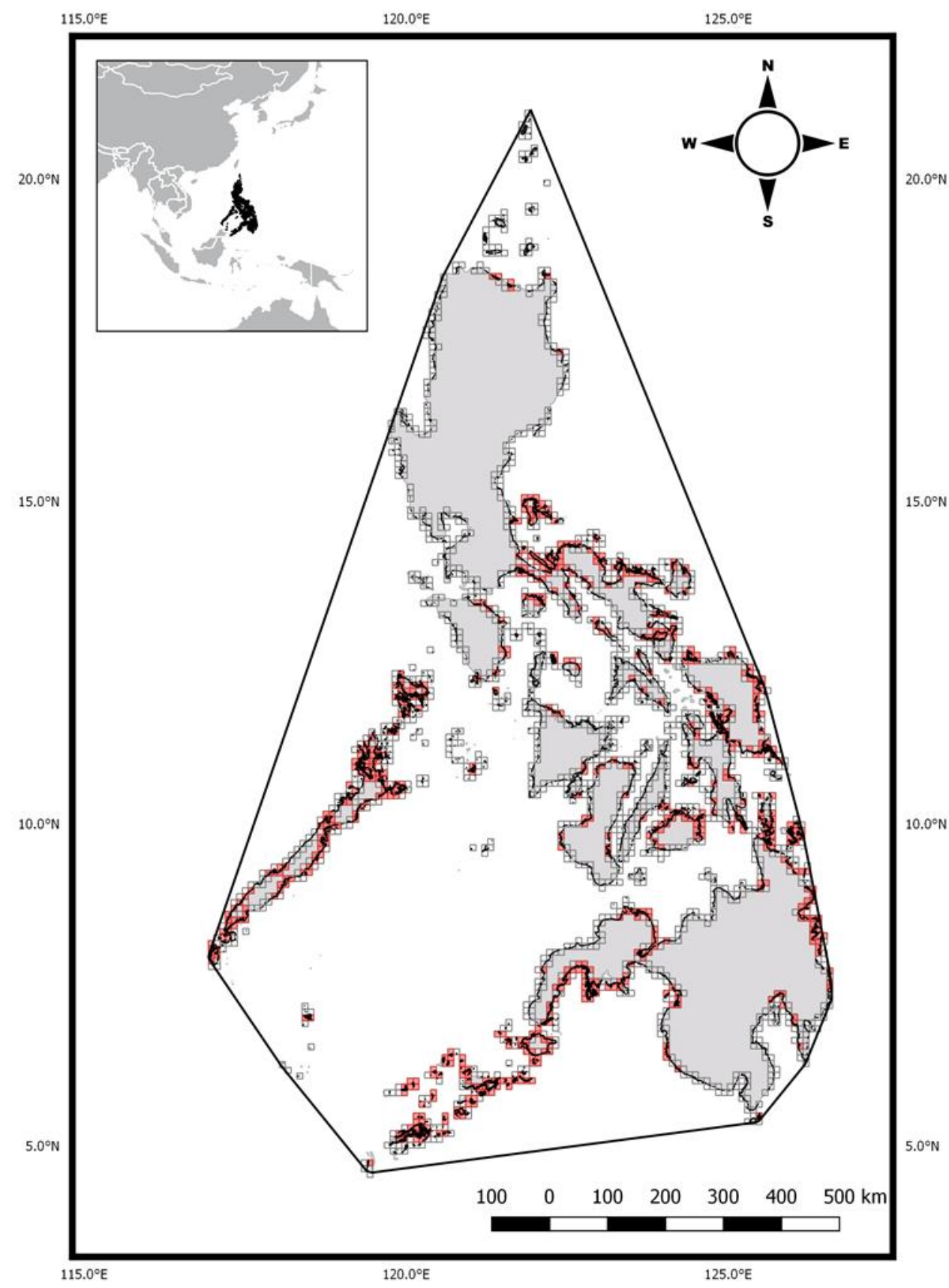

Figure 2. The mapped distribution of the Philippines' fringe mangrove forests and its assessment under Criterion B of the IUCN RLE. Black areas show the mapped distribution of fringe mangrove at $30 \mathrm{~m}$ resolution. The thick black line indicates the EOO (extent of occurrence) of the ecosystem. The dark grey grid cells represent areas of $10 \times 10-\mathrm{km}$ and indicate the $\mathrm{AOO}$ (area of occupancy) of the ecosystem $(A O O=2140)$; cells shaded red indicate the $A O O$ with the $1 \%$ rule $(A O O=621)$. The location of the study area is shown in an inset. 
Annual mean NDVI values for both 2000 and 2016 could be calculated for 8894 cloud-free pixels. Around $22 \%$ of these pixels $(n=1947)$ showed a significant trend $(p$ $<0.05$ ) in annual NDVI values over the 17-year time-series $2000-2016$, of which $63 \%$ $(n=1236)$ exhibited an increase in NDVI value whilst the rest exhibited a decrease (Table 5). Inspection of these pixels showed them to be distributed randomly across the study area, only sometimes occurring in clusters of several pixels with similar trends. Comparison with high resolution Google satellite imagery from 2016-2017 and the 2016 map of fringe mangrove did not show a systematic relationship between pixels exhibiting a decreasing trend and evidence of mangrove degradation, with both increasing and decreasing pixels coinciding with both apparently healthy mangrove forest and other land-cover types (e.g. aquaculture ponds). This undermines the choice of this variable as a suitable indicator of collapse for fringe mangrove forests in the Philippines. Combined with the absence of a satisfactorily robust method of projecting the 17-year time-series data to the 50-year period required for the assessment, this caused the ecosystem to be classed as Data Deficient under subcriteria D1, D2 and D3.

Table 5. The relative severity of the decline in NDVI 2000-2050 assuming PRD or ARD as calculated from the decline between 2000 and 2016. The proportion of pixels showing each relative severity of NDVI decline was assumed to correspond to the fraction of the extent of the ecosystem affected. $C R$ = Critically Endangered; EN $=$ Endangered $; \mathrm{VU}=$ Vulnerable.

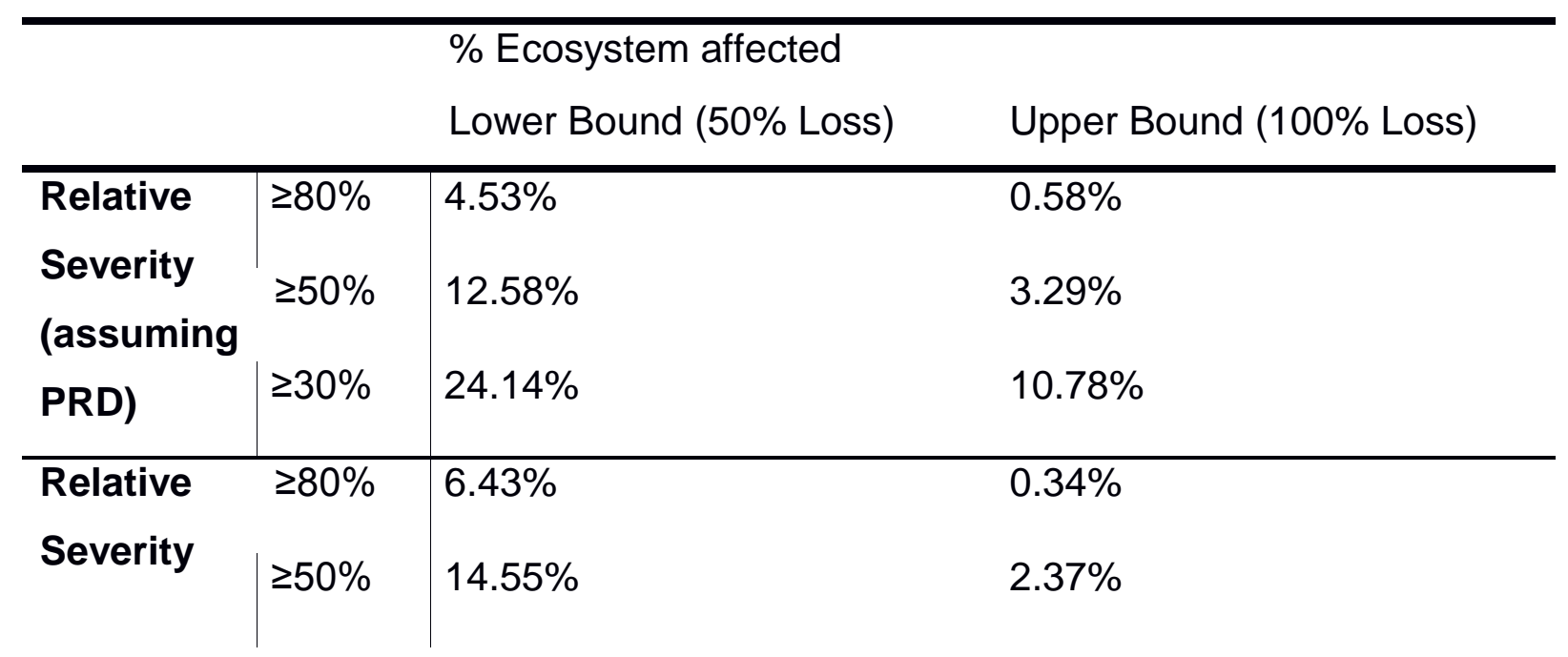


CR: Rel. severity $\geq 80 \%+\geq 80 \%$ extent

EN: Rel. severity $\geq 50 \%+\geq 80 \%$ extent / $\geq 80 \%+\geq 50 \%$ extent

VU: Rel. severity $\geq 30 \%+\geq 80 \%$ extent $/ \geq 50 \%+\geq 50 \%$ extent $/ \geq 30 \%+\geq 80 \%$ extent

\section{DISCUSSION}

The RLE risk assessment provides support for classifying fringe mangroves in the Philippines as 'Least Concern', based on small projected changes in geographic distribution (Criterion A) and their currently large extent (Criterion B; Table 4). Given that mangroves in the Philippines have generally undergone deforestation and degradation (Garcia, Malabrigo \& Gevaña, 2014), this may seem surprising. The large variability in projected distribution changes might in part be underpinned by differences in classification errors between the 2000 and 2016 mangrove maps used for change detection. However, given the overall high user accuracy for fringe mangroves $(\sim 92 \%)$, it is unlikely that the ecosystem as a whole experienced a severe decline in distribution which went undetected. This conclusion is supported by the observation that many of the threats and declines documented for mangrove forests in general are unlikely to affect fringe mangrove forests in particular. For example, aquaculture development is well documented as the leading cause of mangrove deforestation in the Philippines (Primavera, 2000), but this process likely affects fringe mangroves comparatively less, since basin and riverine mangrove forests in higher intertidal regions are often cleared first for the construction of aquaculture ponds. Indeed, almost half of mangrove species found primarily in these regions are currently at increased risk of extinction, compared to less than a third of species primarily found in fringe forest areas (Primavera \& Esteban, 2008; Walters et al., 2008; Polidoro et al., 2010). Additionally, fringe mangrove forests may have benefitted from enhanced levels of conservation, lowering their overall risk of collapse. Fringe mangrove ecosystems have become highly valued in the Philippines for their coastal protection properties (Duncan et al., 2016), and laws mandating the conservation of mangrove greenbelts have resulted in strips of fringe mangrove 
forest being left standing along coasts, even where inland mangrove forests have been degraded (Malik, Fensholt \& Mertz, 2015). Additionally, mangrove replanting as part of rehabilitation schemes is often focused around former fringe mangrove forest areas (Primavera, 2000; Primavera, Rollon \& Samson, 2011). Although mangrove greenbelt and buffer zones are only sporadically enforced (e.g. Duncan et al., 2016), and the long-term survival rate of replanted mangroves is low (10-20\%; Garcia et al., 2014), the combined conservation, protection, and replanting efforts may have reduced the net deforestation of fringe mangrove forests.

Whilst theoretical and practical difficulties of defining and measuring risk of ecosystem collapse have been discussed in general (Sato \& Lindenmayer, 2017), this case study highlights some unique challenges for assessing collapse risk in ecosystems depending on a few foundation species. In such ecosystems, the range of candidate indicators for symptoms of ecosystem collapse is likely to be small, since most pathways to collapse will cluster around a small number of foundation species (e.g. Figure 1). In cases where the ecology and distribution of these species are poorly understood and/or documented, the scope for a quantitative risk assessment will be severely limited, even though the identification of such species itself as useful bioindicators is relatively straightforward. This also means that problems with data availability and quality for any given indicator (cf. Table 4) are likely to be a bigger challenge for ecosystems with few foundation species than others, because there are fewer alternative appropriate indicators. Drawing on our case study, we discuss strategies to overcoming these challenges for data-poor ecosystems (summarised in Figure 3). 


\section{(a) Conceptual basis}

Construct conceptual ecosystem model

Identify all FS $\longrightarrow$ Identify candidate indicators

Evaluate indicators over RLE timeframe

\section{(b) Quantifying risk}

Criterion A: Reduction in geographic distribution

Criterion B: Restricted geographic distribution

Criterion C: Environmental degradation

Criterion D: Disruption of biotic processes or

interaction

Criterion E: Quantitative analysis of the probability of ecosystem collapse

Preferred steps

-......

Alternative steps
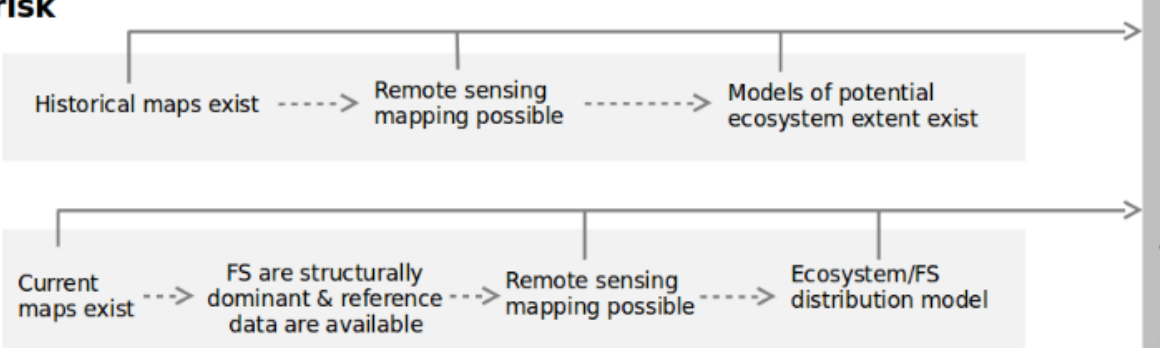

mapping possible

distribution mode

maps exist

surement

Direct measurement
of abiotic parameter possible

Proxy indicator available

Effect of abiotic threats on FS

known

Figure 3. Overview over the steps required to assess collapse risk for ecosystems dependent on a small number of foundation species (sensu Dayton et al., 1972). Before assessment, constructing a conceptual ecosystem model will help to guide selecting appropriate indicators of collapse (a). During assessment, it helps assess alternative candidate data sets or analytical approaches, and therefore compare time constraints associated with each decision (b). The arrows in (b) illustrate which data sources and approaches are preferable. FS=Foundation species. 
As satellite data availability continues to grow and the range of spatial, temporal and spectral resolutions of satellite imagery continues to expand, advances in analytical techniques and processing capacity have enabled researchers to distinguish between subtly different types of land cover categories (e.g. Dierssen, Zimmerman, Drake \& Burdige, 2010; Lucas et al., 2011). Such developments have made it possible to increase the number of ecosystems where changes in distribution can be relatively cheaply assessed, particularly those ecosystems in which foundation species dominate land cover structurally. The main bottleneck for such mapping efforts is the availability and reliability of reference data to train classification algorithms and/or validate ecosystem maps. Appropriate reference data are generally available to assess current extent: in the absence of ground-truth data, open access imagery with very high spatial resolution (e.g. from Google Earth) can indeed often be used, as in this case study. Alternatively, such imagery can be obtained from commercial satellites (e.g. Giri et al., 2008). The recent move towards developing low-cost, small satellites (so-called smallsats or cubesats; Marvin et al., 2016) is likely to improve even further the availability of these types of imagery, although making these data affordable over large spatial scales remains a challenge. Citizen science approaches to land cover classification (Fritz et al. 2017) are a second potential avenue towards developing and improving current maps at large spatial scales for data-poor ecosystems. However, reference data for historical distributions is likely to be scarcer (as was the case for fringe mangroves, see also Long et al., 2014), although aerial imagery and historical maps or other ground-truth data can enable the production of remote-sensing derived maps of ecosystem distribution as far back as the 1960s or 1970s in some cases (Gilman, Ellison \& Coleman, 2007; Giri et al., 2008).

Risk assessments have to assess potential declines or degradation, or alternatively project future distributions, across relatively long time frames (e.g. 50 years for the RLE). In ecosystems that depend on a few foundation species with high longevity, such as mangrove trees, the short-term monitoring of long-lived mature individuals may not provide a sensitive indicator for changes in ecosystem extents relevant to assessments such as the RLE (Keith et al., 2013; Bland et al., 2016). For some areas, there may be appropriate quantitative data to reconstruct distribution of foundation species at a relevant temporal extent; this may be particularly true for 
ecosystems with long-standing economic importance (such as marine and coastal ones; e.g. zu Ermgassen et al., 2012). Alternatively, historical distribution could be approximated using potential ecosystem maps based on a strong causal understanding between environmental variables (e.g. climate or topography) and ecosystem distribution (as approximated by plant communities, e.g. demonstrated by Prentice et al., 1992; Crespin et al., 2015). In the case of fringe mangroves in the Philippines, one way forward would be to build on the global distribution models for fringe mangrove foundation species (Record, Charney, Zakaria and Ellison, 2013), which are based on climatic variables, by introducing variables that shape their distribution at smaller spatial scales (such as sea level and topography). In cases where neither relevant historical data nor potential distribution models are available, short-term trends of distribution change can be extrapolated to project future distributions, as was done in our case study. However, variability in predicted distributions based on short-term trends may exceed real changes, which means the former strategies are preferred.

If the response of foundation species to threats and consequent changes in their functioning are poorly understood, identifying pertinent variables for assessment of abiotic degradation will be challenging, with alternative variables based on nonfoundation species unlikely to be relevant. For example, uncertainty around the responses of fringe mangroves to changes in hydroperiod and sea level rise precluded, in our case, the assessment of abiotic degradation. By contrast, when responses of foundation species to changes in abiotic parameters are well understood, this information can be reliably used to assess abiotic degradation. For instance, in the River Red Gum and Black Box floodplains in Australia, tree die back was gauged to be linked to declines in river flow, a key aspect of abiotic degradation for this system (Keith et al., 2013). The same is true for detecting disruption of biotic interactions (under Criterion D); here, indicators need to be sensitive to changes in the role of the foundation species in shaping ecosystem functioning (see e.g. Alvarez-Filip, 2009; Bland et al., 2016). For instance, habitat and shelter provision by kelp forests in Alaska depends on kelp density, which can then be used to assess biotic interactions for this system (Keith et al., 2013). Similarly, coral cover or surface rugosity has been suggested as a proxy for biotic interactions for coral reefs (Keith et al., 2013). However, in this particular case study, the chosen indicator (a proxy for 
NPP) did not seem sensitive to ecosystem degradation, and datasets for alternative variables were not available, meaning that this functional criterion could not be assessed. In such cases, variables sensitive to symptoms of degradation at shorter temporal scales could be used to estimate collapse risk from abiotic degradation or interruption of biotic interactions. Such variables reflect elevated risks of future decline, and will likely be proxies of population growth rate of the foundation species, such as survival/recruitment (Keith et al., 2013) or population age structure (Burns et al., 2015). For fringe mangroves, seedling recruitment could be used to detect mangrove species declines before they manifest in altered distribution of adults (Padilla et al., 2004). Where age or stand structure information is available, population viability analyses for foundation species could also contribute to more robust estimates of ecosystem collapse risk (Menges, 2000).

\section{Conclusion}

Integrating different types of data via satellite remote sensing, GIS and modelling approaches is a promising way to meet the unique demands of risk assessments for ecosystems depending on a few foundation species. The conceptual ecosystem model at the heart of the RLE assessment protocol is central to structuring both the identification of relevant data sets and for the integration process, including the development of quantitative models to address particular indicators. Gathering new data will be necessary in some cases, as will be the continuation of existing monitoring programmes (including satellite remote sensing) to provide sufficiently long time series. Our study illustrates that despite these constraints a large range of valuable tools are already available to assess the risk of collapse for ecosystems dominated by foundation species. 


\section{ACKNOWLEDGEMENTS}

We would like to thank Calvin Lee and Clare Duncan for valuable advice on mangrove ecology and for sharing technical expertise.

\section{CONFLICTS OF INTEREST}

The authors declare no conflicts of interest.

\section{FUNDING}

This research did not receive any specific grant from funding agencies in the public, commercial, or not-for-profit sectors.

\section{DATA ACCESSIBILITY STATEMENT}

The fringe mangrove maps are available from the corresponding author upon request.

The code used in the land cover classification and NDVI time series analysis is available on email request to the corresponding author. 


\section{REFERENCES}

Alongi, D.M. (2008). Mangrove forests: Resilience, protection from tsunamis, and responses to global climate change. Estuarine, Coastal and Shelf Science, 76, $1-13$.

Alongi, D.M. (2014). Carbon Cycling and Storage in Mangrove Forests. Annual Review of Marine Science, 6, 195-219.

Alvarez-Filip, L., Dulvy, N. K., Gill, J. A., Côté, I. M., \& Watkinson, A. R. (2009). Flattening of Caribbean coral reefs: region-wide declines in architectural complexity. Proceedings of the Royal Society of London B: Biological Sciences, 276, 3019-3025.

Barbier, E.B., Hacker, S.D., Kennedy, C., Koch, E.W., Stier, A.C., \& Silliman, B.R. (2011). The value of estuarine and coastal ecosystem services. Ecological Monographs, 81, 169-193.

Bland, L.M., Keith, D.A., Miller, R.M., Murray, N.J., \& Rodríguez, J.P. (2016). Guidelines for the application of IUCN Red List of ecosystems categories and criteria, Version 1.0. IUCN, Gland, Switzerland.

Boitani, L., Mace, G.M., \& Rondinini, C. (2015). Challenging the Scientific Foundations for an IUCN Red List of Ecosystems. Conservation Letters, 8, 125131.

Brander, L.M., Wagtendonk, A.J., Hussain, S.S., McVittie, A., Verburg, P.H., de Groot, R.S., \& van der Ploeg, S. (2012). Ecosystem service values for mangroves in Southeast Asia: A meta-analysis and value transfer application. Ecosystem Services, 1, 62-69.

Buelow, C., Sheaves, M. (2015). A birds-eye view of biological connectivity in mangrove systems. Estuarine, Coastal and Shelf Science, 152, 33-43.

Burns, E.L., Lindenmayer, D.B., Stein, J., Blanchard, W., McBurney, L., Blair, D., \& Banks, S.C. (2015). Ecosystem assessment of mountain ash forest in the Central Highlands of Victoria, south-eastern Australia. Australian Ecology, 40, 386-399.

Connette, G., Oswald, P., Songer, M., \& Leimgruber, P. (2016). Mapping Distinct 
Forest Types Improves Overall Forest Identification Based on Multi-Spectral Landsat Imagery for Myanmar's Tanintharyi Region. Remote Sensing, 8, 882.

Crespin, S. J., \& Simonetti, J. A. (2015). Predicting ecosystem collapse: spatial factors that influence risks to tropical ecosystems. Australian Ecology, 40(4), 492-501.

Davidson, N. C. (2014). How much wetland has the world lost? Long-term and recent trends in global wetland area. Marine and Freshwater Research, 65, 934941.

Day, J. W., Coronado-Molina, C., Vera-Herrera, F. R., Twilley, R., Rivera-Monroy, V. H., Alvarez-Guillen, H., ... \& Conner, W. (1996). A 7 year record of aboveground net primary production in a southeastern Mexican mangrove forest. Aquatic Botany, 55(1), 39-60.

Dayton, P.K. (1972). Toward an understanding of resilience and the potential effects of enrichments to the benthos at McMurdo Sound, Antarctica, in: Parker, B.C. (Ed.), Proceedings of the Colloquium of Conservation Problems in Antarctica. Allen Press, Lawrence, Kansas, pp. 81-96.

Dierssen, H. M., Zimmerman, R. C., Drake, L. A., \& Burdige, D. (2010). Benthic ecology from space: optics and net primary production in seagrass and benthic algae across the Great Bahama Bank. Marine Ecology Progress Series, 411, 1 15.

Dobson, A., Lodge, D., Alder, J., Cumming, G. S., Keymer, J., McGlade, J., ... Wall, D. (2006). Habitat loss, trophic collapse, and the decline of ecosystem services. Ecology, 87(8), 1915-1924.

Duke NC, Ball MC, \& Ellison JC. (1998). Factors Influencing Biodiversity and Distributional Gradients in Mangroves. Global Ecology \& Biogeography Letters, $7(1), 27-47$

Duncan, C., Primavera, J.H., Pettorelli, N., Thompson, J.R., Loma, R.J.A., Koldewey, H.J. (2016). Rehabilitating mangrove ecosystem services: A case study on the relative benefits of abandoned pond reversion from Panay Island, Philippines. Marine Pollution Bulletin, 109, 772-782.

Effiom, E. O., Nuñez-Iturri, G., Smith, H. G., Ottosson, U., \& Olsson, O. (2013). 
Bushmeat hunting changes regeneration of African rainforests. Proceedings of the Royal Society of London B: Biological Sciences, 280(1759), 20130246.

Ellison, J.C. (2005). Holocene palynology and sea-level change in two estuaries in Southern Irian Jaya. Palaeogeography Palaeoclimatology Palaeoecology, 220, 291-309.

Ellison, A.M., Bank, M.S., Clinton, B.D., Colburn, E.A., Elliott, K., Ford, C.R., ..., Webster, J.R. (2005). Loss of foundation species: consequences for the structure and dynamics of forested ecosystems. Front. Ecol. Environ. 3, 479486. doi:10.1890/1540-9295(2005)003[0479:LOFSCF]2.0.CO;2

Ewel, K.C., Twilley, R.R., \& Ong, J.E. (1998). Different Kinds of Mangrove Forests Provide Different Goods and Services. Global Ecolology and Biogeography Letters, 7, 83-94.

FAO (2007). Mangroves of Asia 1980-2005: Country Reports. Food and Agriculture Organization of the United Nations.

Farley, J., Batker, D., de la Torre, I., \& Hudspeth, T. (2010). Conserving Mangrove Ecosystems in the Philippines: Transcending Disciplinary and Institutional Borders. Environmental Management, 45, 39-51.

Folke, C., Carpenter, S., Walker, B., Scheffer, M., Elmqvist, T., Gunderson, L., \& Holling, C. S. (2004). Regime shifts, resilience, and biodiversity in ecosystem management. Annual Review of Ecology, Evolution, and Systematics, 35, 557581.

Forkel, M., Carvalhais, N., Verbesselt, J., Mahecha, M. D., Neigh, C. S., \& Reichstein, M. (2013). Trend change detection in NDVI time series: Effects of inter-annual variability and methodology. Remote Sensing, 5, 2113-2144.

Forkel M,, \& Wutzler T. (2015) greenbrown - land surface phenology and trend analysis. A package for the R software. Version 2.2, 2015-04-15, http://greenbrown.r-forge.r-project.org/

Fritz, S., See, L., Perger, C., Mccallum, I., Schill, C., Schepaschenko, D., ... Lesiv, M. (2017). A global dataset of crowdsourced land cover and land use reference data. Scientific Data, 4, 170075.

Garcia, K.B., Malabrigo, P.L., \& Gevaña, D.T. (2014). Philippines' Mangrove 
Ecosystem: Status, Threats and Conservation, in: Faridah-Hanum, I., Latiff, A., Hakeem, K.R., Ozturk, M. (Eds.), Mangrove Ecosystems of Asia (pp. 81-94). New York: Springer.

GDAL Development Team (2016). GDAL - Geospatial Data Abstraction Library, Version 1.11.4.

Geist, S.J., Nordhaus, I., \& Hinrichs, S. (2012). Occurrence of species-rich crab fauna in a human-impacted mangrove forest questions the application of community analysis as an environmental assessment tool. Estuarine, Coastal and Shelf Science, 96, 69-80.

Gilman, E., Ellison, J., \& Coleman, R. (2007). Assessment of mangrove response to projected relative sea-level rise and recent historical reconstruction of shoreline position. Environmental monitoring and assessment, 124(1), 105-130.

Gilman, E.L., Ellison, J.C., Duke, N.C., \& Field, C. (2008). Threats to mangroves from climate change and adaptation options: A review. Aquatic Botany, 89, 237250.

Giri, C., Zhu, Z., Tieszen, L. L., Singh, A., Gillette, S., \& Kelmelis, J. A. (2008). Mangrove forest distributions and dynamics (1975-2005) of the tsunamiaffected region of Asia. Journal of Biogeography, 35(3), 519-528.

Giri, C., Ochieng, E., Tieszen, L.L., Zhu, Z., Singh, A., Loveland, T.R., Masek, J., \& Duke, N.C., (2011). Status and distribution of mangrove forests of the world using earth observation satellite data. Global Ecology and Biogeography, 20, 154-159.

Haddad, N. M., Brudvig, L. A., Clobert, J., Davies, K. F., Gonzalez, A., Holt, R. D., ..., Townshend, J. R. (2015). Habitat fragmentation and its lasting impact on Earth's ecosystems. Science Advances, 1, e1500052.

Hamilton, S.E., \& Casey, D., (2016). Creation of a high spatio-temporal resolution global database of continuous mangrove forest cover for the 21st century (CGMFC-21). Global Ecology and Biogeography, 25, 729-738.

Hansen, M. C., Potapov, P. V., Moore, R., Hancher, M., Turubanova, S. A., Tyukavina, A., ..., Townshend, J.R.G. (2013). High-resolution global maps of 21 st-century forest cover change. Science, 342, 850-853. 
Harrison, R. D., Tan, S., Plotkin, J. B., Slik, F., Detto, M., Brenes, T., ... Davies, S. J. (2013). Consequences of defaunation for a tropical tree community. Ecology letters, 16(5), 687-694.

Heithaus, R.E., Heithaus, P.A., Heithaus, M.R., Burkholder, D., \& Layman, C.A.(2011). Trophic dynamics in a relatively pristine subtropical fringing mangrove community. Marine Ecology Progress Series, 428, 49-61.

Hijmans, R.J., Garcia, N., \& Wieczorek, J., 2015. Global Administrative Areas Database (GADM), Version 2.8 [WWW Document]. URL http://www.gadm.org (accessed 2.23.17).

IUCN (2012). Habitats Classification Scheme, Version 3.1 [WWW Document]. URL http://www.iucnredlist.org/technical-documents/classification-schemes/habitatsclassification-scheme-ver3 (accessed 1.30.17).

Jackson, J. B., Kirby, M. X., Berger, W. H., Bjorndal, K. A., Botsford, L. W., Bourque, B. J., ... Hughes, T. P. (2001). Historical overfishing and the recent collapse of coastal ecosystems. Science, 293, 629-637.

Kathiresan, K., \& Bingham, B.L. (2001). Biology of mangroves and mangrove Ecosystems. Advances in Marine Biology, 40, 81-251.

Keith, D.A., Rodríguez, J.P., Rodríguez-Clark, K.M., Nicholson, E., Aapala, K., Alonso, ..., Zambrano-Martinez, S. (2013). Scientific Foundations for an IUCN Red List of Ecosystems. PLoS One, 8, e62111.

Keith, D.A. (2015). Assessing and managing risks to ecosystem biodiversity. Australian Ecology, 40, 337-346.

Krauss, K.W., Lovelock, C.E., McKee, K.L., López-Hoffman, L., Ewe, S.M.L., \& Sousa, W.P. (2008). Environmental drivers in mangrove establishment and early development: A review. Aquatic Botany, 89, 105-127.

Kristensen, E., Bouillon, S., Dittmar, T., \& Marchand, C. (2008). Organic carbon dynamics in mangrove ecosystems: A review. Aquatic Botany, 89, 201-219.

Lee, S.Y. (1998). Ecological role of grapsid crabs in mangrove ecosystems: a review. Marine and Freshwater Research, 49, 335-343.

Lee, S.Y., Primavera, J.H., Dahdouh-Guebas, F., McKee, K.L., Bosire, J.O., Cannicci, S., ..., Record, S. (2014). Ecological role and services of tropical 
mangrove ecosystems: a reassessment. Global Ecology and Biogeography, 23, 726-743.

Leutner, B., \& Horning, N. (2017). RStoolbox: Tools for Remote Sensing Data Analysis. R package version 0.1.10. https://CRAN.Rproject.org/package=RStoolbox

Long, J.B., \& Giri, C. (2011). Mapping the Philippines' Mangrove Forests Using Landsat Imagery. Sensors, 11, 2972-2981.

Long, J.B., Napton, D., Giri, C., \& Graesser, J. (2014). A Mapping and Monitoring Assessment of the Philippines' Mangrove Forests from 1990 to 2010. Journal of Coastal Research, 294, 260-271.

Lucas, R., Medcalf, K., Brown, A., Bunting, P., Breyer, J., Clewley, D., ... Blackmore, P. (2011). Updating the Phase 1 habitat map of Wales, UK, using satellite sensor data. ISPRS Journal of Photogrammetry and Remote Sensing, 66, 81102.

Lugo A.E,, Snedaker S.C. (1974) The Ecology of Mangroves. Annual Review of Ecology, Evolution, and Systematics, 5, 39-64.

Mattiuzzi, M., \& Detsch, F. (2018). MODIS: Acquisition and Processing of MODIS Products. R package version 1.1.2. https://CRAN.Rproject.org/package=MODIS

Malik, A., Fensholt, R., \& Mertz, O. (2015). Mangrove exploitation effects on biodiversity and ecosystem services. Biodiversity and Conservation, 24, 35433557.

Marvin, D. C., Koh, L. P., Lynam, A. J., Wich, S., Davies, A. B., Krishnamurthy, R., ... Asner, G. P. (2016). Integrating technologies for scalable ecology and conservation. Global Ecology and Conservation, 7, 262-275.

Menges, E. S. (2000). Population viability analyses in plants: challenges and opportunities. Trends in Ecology \& Evolution, 15, 51-56.

Millennium Ecosystem Assessment (2005). Ecosystems and Human Well-Being: Biodiversity Synthesis. World Resources Institute, Washington, DC.

Murray, N.J., Miller, R.M., Zager, I., Keith, D.A., Bland, L.M., Esteves, R., OliveiraMiranda, M.A., \& Rodríguez, J.P. (2016). Introduction to the IUCN Red List of 
Ecosystems Categories and Criteria: Course Manual, Version 1.0.

Nagelkerken, I., Blaber, S.J.M., Bouillon, S., Green, P., Haywood, M., Kirton, L.G., Meynecke, J.-O., Pawlik, J., Penrose, H.M., Sasekumar, A., \& Somerfield, P.J. (2008). The habitat function of mangroves for terrestrial and marine fauna: A review. Aquatic Botany, 89, 155-185.

Padilla, C., Fortes, M.D., Duarte, C.M., Terrados, J., \& Kamp-Nielsen, L. (2004). Recruitment, mortality and growth of mangrove (Rhizophora sp.) seedlings in Ulugan Bay, Palawan, Philippines. Trees, 18, 589-595.

Pettorelli, N. (2013). The normalized difference vegetation index. Oxford University Press.

Polidoro, B.A., Carpenter, K.E., Collins, L., Duke, N.C., Ellison, A.M., Ellison, J.C., ..., Yong, J.W.H. (2010). The Loss of Species: Mangrove Extinction Risk and Geographic Areas of Global Concern. PLoS One, 5, e10095.

Prentice, I. C., Cramer, W., Harrison, S. P., Leemans, R., Monserud, R. A., \& Solomon, A. M. (1992). Special paper: a global biome model based on plant physiology and dominance, soil properties and climate. Journal of Biogeography, 19, 117-134.

Primavera, J.H. (2000). Development and conservation of Philippine mangroves: institutional issues. Ecological Economics, 35, 91-106.

Primavera, J.H. \& Esteban, J.M.A. (2008). A review of mangrove rehabilitation in the Philippines: successes, failures and future prospects. Wetlands Ecology and Management, 16, 345-358.

Primavera, J.H., Rollon, R.N., \& Samson, M.S. (2011). The Pressing Challenges of Mangrove Rehabilitation, in: L. Chicharo \& M. Zalewski (Eds.), Ecohydrology and restoration: treatise on estuarine and coastal science (pp. 217-244).

Amsterdam: Elsevier.

QGIS Development Team (2016). QGIS Geographic Information System.

R Core Team (2016). R: A Language and Environment for Statistical Computing. Raudsepp-Hearne, C., Peterson, G. D., Tengö, M., Bennett, E. M., Holland, T., Benessaiah, K., ... Pfeifer, L. (2010). Untangling the environmentalist's paradox: Why is human well-being increasing as ecosystem services degrade? 
BioScience, 60(8), 576-589.

Record, S., Charney, N. D., Zakaria, R. M., \& Ellison, A. M. (2013). Projecting global mangrove species and community distributions under climate change. Ecosphere, 4(3), 1-23.

Ricklefs, R.E. \& Latham, R.E. (1993). Global Patterns of Diversity in Mangrove Floras. In: Ricklefs, R.E. \& Schluter, D. (Eds.), Species Diversity in Ecological Communities: Historical and Geographical Perspectives (pp. 215-229). Chicago, IL: University of Chicago Press.

Sato, C. F. \& Lindenmayer, D. B. (2017). Meeting the Global Ecosystem Collapse Challenge. Conservation Letters, in press.

Sinfuego, K.S. \& Buot, I.E. (2008). Floristic Composition and Analysis of the True Mangrove Vegetation in the Philippine Islands. Journal of Nature Studies, 7, 8390.

Sinfuego, K.S. \& Buot, I.E. (2014). Mangrove zonation and utilization by the local people in Ajuy and Pedada Bays, Panay Island, Philippines. Journal of Marine and Island Cultures, 3, 1-8.

Soares, M.L.G. (2009). A Conceptual Model for the Responses of Mangrove Forests to Sea Level Rise. Journal of Coastal Research, 1, 267-271.

Solano, R., Didan, K., Jacobson, A., \& Huete, A. (2010). MODIS Vegetation Index User's Guide ( MOD13 Series ). University of Arizona 2010, 38. Accessible at https://vip.arizona.edu/MODIS_UsersGuide.php, access 05/07/2017.

Stoner, K. E., Vulinec, K., Wright, S. J., \& Peres, C. A. (2007). Hunting and plant community dynamics in tropical forests: a synthesis and future directions. Biotropica, 39(3), 385-392.

Terborgh, J., Nuñez-Iturri, G., Pitman, N. C., Valverde, F. H. C., Alvarez, P., Swamy, V., ... Paine, C. E. (2008). Tree recruitment in an empty forest. Ecology, 89(6), 1757-1768.

Twilley, R.R., Snedaker, S.C., Yáñez-Arancibia, . \& Medina, E. 1996. Biodiversity and Ecosystem Processes in Tropical Estuaries: Perspectives of Mangrove Ecosystems. In: Functional Roles of Biodiversity: A Global Perspective $(\mathrm{H}$. A. Mooney et al., eds), pp. 327-370. John Wiley \& Sons, Ltd. 
Vermote, E., Justice, C.O., Claverie, M., \& Franch, B. (2016). Preliminary analysis of the performance of the Landsat 8/OLI land surface reflectance product. Remote Sensing of the Environment, 185, 46-56.

Walters, B.B., Rönnbäck, P., Kovacs, J.M., Crona, B., Hussain, S.A., Badola, R., ..., Dahdouh-Guebas, F. (2008). Ethnobiology, socio-economics and management of mangrove forests: A review. Aquatic Botany, 89, 220-236.

Wegmann, M., Leutner, B., \& Dech, S. (2016). Remote Sensing and GIS for ecologists: Using Open Source Software. Exeter: Pelagic Publishing, UK.

$\mathrm{Xu}, \mathrm{H}$. (2006). Modification of normalised difference water index (NDWI) to enhance open water features in remotely sensed imagery. International journal of remote sensing, 27(14), 3025-3033.

Zu Ermgassen, P. S., Spalding, M. D., Blake, B., Coen, L. D., Dumbauld, B., Geiger, S.,... Rodney, W. (2012). Historical ecology with real numbers: past and present extent and biomass of an imperilled estuarine habitat. Proceedings of the Royal Society B, 279, 3393-3400. 